\title{
AIR PASSENGERS VERTEX CURVE THEOREM - EVIDENCE FROM ASEAN COUNTRIES
}

\author{
Mohd Azlan Abdul \\ Majid $^{1}$ \\ (D) Faridah Pardi ${ }^{2}$ \\ Afizan Amer ${ }^{3}$ \\ Nor' Azurah Md \\ Kamdari $^{4}$ \\ Sarah Mardhiah \\ Selamat $^{5}$
}

\author{
${ }_{1,2, s, \ldots, 5}$ Faculty of Business Management, Universiti Teknologi MARA (Negeri \\ Sembilan), Malaysia. \\ 'Email: mohda164@uitm.edu.myTel:+6013 3305465 \\ 'Email:faridah405@uitm.edu.myTel:+60199871942 \\ 'Email:afizanamer@uitm.edu.myTel: +60136818515 \\ "Email:myroazurah@omail.com Tel: +6016 6384043 \\ ${ }^{5}$ Email:sarah468@uitm.edu.myTel: +6016 4413858
}

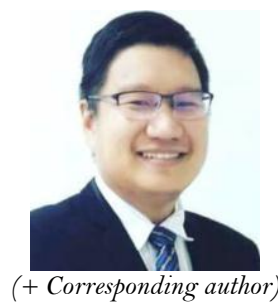

\section{Article History}

Received: 29 November 2018 Revised: 31 December 2018 Accepted: 6 February 2019 Published: 27 March 2019

\section{Keywords}

Air passenger

ASEAN aviation

VERTEX curve

Static panel

Policy impact hypotheses

Digital impact hypothese

Macroeconomics impact

hypotheses.

JEL Classification: F62, F68, L93, L96, O00

\begin{abstract}
This study examines new generic hypotheses and theorems of the aviation industry's model for air passengers for ASEAN countries. A static panel data model consists of a simple panel unit and root and cointegration tests were established for the period from 1997 to 2016. Initially, we hypothesized that internet connection, income level, tax and tourism expenditures all have significant impacts on the volume of air passengers in ASEAN countries. Our main findings showed that gross national income (GNI) has a positive significant impact on air passengers' volume and it is also the peak of the vertex. In addition, according to the hypothesized vertex theorem, the policy-impact of taxation on air passenger volume showed a weak significance, while the digital-impact hypothesis of broadband and mobile technology exhibited a mediocre and substitution impact. Our conclusion from the findings highlighted that fundamentals of domestic economic growth should be strengthened in order to increase internal economic capacity. By achieving this, the volume of the air passenger could be doubled and therefore would bring back a growth of income and prosperity to the nation, particularly in the ASEAN market.
\end{abstract}

Contribution/ Originality: This study developed a new Vertex curve theorem based on macro analysis in the ASEAN aviation market.

\section{INTRODUCTION}

Since early civilization, transportation has been important. Such an importance can be seen from the first invention of wheel in $4500 \mathrm{BCE}$, to the breaking of the modern sound barrier on an industrial scale by the Concord in the 1980s. This paper wills investigate and explore the relationships between the new digital age of technology, economic policy and the volume of air passengers in the aviation industry.

In the model of policies and tourism between China and Taiwan, Wu et al. (2018) emphasized the time series data technique model. However, frequency analysis was employed by Lee and Fukunaga (2014) to define the ASEAN cooperation in precise. Both of these techniques eventually highlighted the gap of study: there is substantial amount of literature focusing on time series analysis and some transportation literature in ASEAN cases are based on a simple panel frequency analysis. Therefore, this study will use a simple static panel analysis for 
ASEAN countries. This paper attempts to answer how digital technology, economic policy and the aviation industry are affected by each other within the ASEAN market. The two major objectives of this article are as follows:

i. To identify the relationships between digital technology, economic policy and the aviation industry's air passenger volume in the ASEAN market, and

ii. To develop a new generalized hypothesis of aviation in the ASEAN market.

\section{LITERATURE}

Most of the literature in this area emphasized the analysis between models and policies, such as from Wu et al. (2018) and Lee and Fukunaga (2014). However, the generalization of econometric analysis adapted for the ASEAN market is found to be deficient in both literatures. Their findings show that promoted schedule service and the regulation of charter flight has affected tourism flow in Taiwan and Mainland China.

The study analyzed the relationships of China and Taiwan's aviation industries with regional politics and policy impacts on air passenger volume and frequency. The questions raised by the previous study have further motivated us to find an answer by testing the related hypotheses in the ASEAN market.

Hanaoka et al. (2014) discussed the ASEAN Single Aviation Market (ASAM) and its impact on Low Cost Carriers (LCC) and Full-Service Carriers (FSC) in the ASEAN market. They found that increasing LCC frequencies would decrease air fare prices. This is because, even if the FSC adapts the LCC fare strategy, the LCC already leads the industry because when there is competition, productivity is increased and the air fares would reduce. The study highlighted the analysis of frequencies in the ASEAN market but did not focus on a generic or contextual analysis of the situation. Frequency analysis is similar to time series analysis in that it depends on a deep analysis of the topic but however, lacks an aggregated perspective. This created a gap in the literature and it became our central objective.

The findings from Hanaoka et al. (2014) have been supported by Tan (2015) which found that the European and ASEAN countries' open sky policy with code sharing is a good strategy and complies with the fourth and fifth freedom. The policy brings benefit to both ASEAN and European aviation companies. Another study by Hensher and Duangphastra (2000) has provided the canonical analysis of ASEAN's aviation industry which concludes that government policies always contradict the airlines' industrial strategies. Even though the hypothesis employed was rather ancient, the two-dimension output inspires our vertex curve hypotheses. Lin and Fu (2014) also supported the hypotheses by Wu et al. (2018) but additionally stated that a new agreement will increase air passenger volume but that the national policy between both states would significantly affect the tourism flow.

The literature used in this study is from past research supporting the argument made by Wu et al. (2018); Hanaoka et al. (2014) and Tan (2015) who attempted to examine ASEAN's aviation industries and Hensher and Duangphastra (2000) who provided the supporting canonical diagram. This study is based on these arguments and presents new ASEAN vertex hypotheses.

The literature suggested that China and Taiwan implemented a lot of cases studies based on specific techniques such as impulse response, an approach that is exceptional but cannot be implemented for the aggregate macro studies. Most of the literature on ASEAN's aviation industries used a lot of simple analysis but lacked generic and specific analysis. Hensher and Duangphastra (2000) have shown the importance of a simple diagram in defining complex issues. Therefore, our vertex hypotheses are based on a combination of these weaknesses and gaps in the research.

\section{METHODOLOGY}

We used quarterly data from the International Monetary Fund (IMF) and the World Bank from 1997 to 2016 for all the ASEAN countries (Brunei, Laos, Myanmar, Singapore, Thailand, Vietnam, Malaysia, Cambodia, 
Indonesia and Philippines). A simple panel data regression consisting of a simple econometric model was estimated below: -

\section{$\ln A I R$ PASSENGER $=\beta_{0}+\beta_{1} \operatorname{lnBROADBAND}+\beta_{2} \operatorname{lnMOBILE}+\beta_{\mathrm{a}} \ln \mathrm{GNI}+\beta_{4} \operatorname{lnTOURISM}+\beta_{5} \operatorname{lnTAX}+\mu_{\mathrm{it}}$}

Whereby lnBROADBAND, lnMOBILE are the digital impact variables, lnGNI and lnTOURISM are the macroeconomic impact variables and $\ln \mathrm{TAX}$ is the policy impact variable.

A rather simple approach is to assume that the airlines passenger volume is correlated with the broadband subscription volume, the amount of mobile cellular connection, the real national income, tourism expenditure and tax revenue. Since our intention was to test the equation's stability, the static panel data technique would be more appropriate compared to the dynamic model.

The second approach is to estimate at least three cointegration models, which indicate that the digital technology (broadband and mobile), macroeconomic variables (GNI and tourism) and policy (tax) would have impact on the air passenger volume.

We also conducted the conventional two panel unit roots tests. First was the Levin et al. (2002) (LLC) panel unit roots test. The model is estimated as follows:

$$
\Delta y_{t}=\alpha+\tau_{t}+\rho y_{i t-1}+c_{i t}+v_{i t}
$$

With the null hypothesis being that $H_{o}: \rho=O$ versus $H_{o}: \rho<O\left(H_{o}\right.$ data is non-stationary; $H_{t}$ data is nonstationary). The second was the IPS (Im, Pesaran and Shin) test as from the Im et al. (2003) presented below:

$$
\Delta y_{i t}=\alpha_{i}+\tau_{t}+\rho_{i} y_{i t-1}+c_{i t}+v_{i t}
$$

$H_{o:} \rho_{i}=O$ vs $H_{o}: \rho_{i}<O$ is based on T-ratio across $i\left(\mathrm{H}_{\mathrm{o}}\right.$ hypothesis is non-stationary; $H_{t}$ hypothesis is nonstationary). Maddala and Wu (1999) suggest the test statistic:

${ }_{2} \sum i \epsilon(1, N) \ln (\rho i) \sim X^{2}(2 N)=\rho_{i}$ : value for ADF regression.

These unit root tests assumed that cross section are uncorrelated, with Pesaran (2007) proposing the following modification to IPS test:

$$
\Delta y_{i t}-\alpha_{i}+\tau_{t}+\rho_{i} y_{i t-1}+\beta \bar{y}_{t-1}+c_{i t}+v_{i t}
$$

With $\bar{y}_{t-1}$ as the proxy for average across cross sections of the common component.

Using only the LLC technique, we determined the stationary level of each unit. Along with this, the IPS technique complemented the non-powerful rejection strength of the LLC. The second approach of the cointegration test was implemented following the determination of stationary data, since it would convey the long-term relationship among components of the model. The test is also important to validate our main research vertex hypotheses.

First we tested it using the Johansen Fisher Panel Cointegration Test. The model was established by Fisher (1970) and is rather old but was updated by Maddala and Wu (1999). The co integration factor in this work was represented by the following:

Digital impact: Air - (Broad + Mobile + GNI + Tourism + Tax $)$,

Macroeconomics impact: Air - (Broad + Mobile + GNI + Tourism + Tax $)$

And;

Policy impact: Air $-($ Broad + Mobile + GNI + Tourism + Tax $)$. 
By doing this, there were at least three underlying cointegration factors to be developed in order to support the vertex hypotheses. The test adopted the similar technique as Johansen's time series of trace and Eigen Statistic values. However, our extended methodology was based on the additional Fisher statistic that employed a similar mechanism as a trace statistic except that the testing was conducted on panel data. The trace statistics are depicted as follows:

Maximum Eigen value:

$$
\lambda_{\max }(r, r+1)=-T \sum \ln \left(1-\lambda_{I-1}\right)
$$

Trace statistic:

$$
\lambda_{\text {TRACE }}(r)=-T \sum \ln \left(I-\lambda_{t}\right)
$$

Whereby:

$\lambda_{I}=$ characteristic root estimate value derived from matrix $\Pi$

$r \quad=$ cointegration factor

$\mathrm{T}$ = observation

The hypothesis of the tests was drawn with the null hypothesis; $H_{0}$ : No cointegration exists (i.e. the model does not exhibit a long-term relationship) while alternative hypothesis, $H_{i}$ : cointegration exists (i.e. the model exhibits a long-term relationship). If the test statistics' values were greater than the critical values (our boundaries of between $1 \%$ to $5 \%$ significant levels), the null hypothesis was rejected, indicating the existence of cointegration with at least one factor.

In validating the test results, we further tested the cointegrating relationships by employing the Kao (EngelGranger Residual Cointegration Test) based on Engle and Granger (1987). These cointegration tests were based on the residual of spurious regression using I(1) variables. If the variables were cointegrated then the residual would be I(O), while if they were not cointegrated, then the residuals would be I(1). Pedroni (1999;2004) and Kao (1999) extended the Engel-Granger framework in order to specifically test the panel data based on a simple model:

$$
Y_{i t}=X_{i t}^{\prime} \beta+Z_{i t}^{\prime} \gamma+e_{i t}
$$

Where $y_{i t}$ and $x_{i t}$ are $\mathrm{I}(1)$.

Kao (1999) proposed the DF and ADF unit root test for $e_{i t}$ as a test for the null cointegration. Kao tested the same basic approach as Pedroni tested but specified the cross section intercepts and homogenous coefficient on the first stage regressors. The enveloped theorem made by Kao (1999) is depicted as follows:

$$
A D F=\frac{t A D F+\sqrt{\sqrt{6 N_{\partial / v}}}}{\sqrt{\frac{a_{0 v}^{2}}{2 a b}+\sqrt{\frac{\mathrm{g} a_{0 v}^{2}}{10 \theta_{0 v}^{2}}}}}
$$

Where the asymptotic values of $D F_{\rho}, D F_{t}, D F_{\rho}^{*}, D F_{t}^{*}$ and $\mathrm{ADF}$ converge to a standard normal distribution $\mathrm{N}$ $(0,1)$ by the sequential limit theory. The $t$ in ADF is the $t$ statistic of $\rho$. Applying similar hypotheses as before, with null hypothesis of $H_{0}$ : no cointegration, $H_{i}$ : Cointegrated. The hypotheses were drawn as in the mechanic above and the Eviews software captured the residual variance of heteroscedasticity and autocorrelation (HAC) as the ADF base. Pedroni (1999;2004) had enveloped the theorem based from Engle and Granger (1987) and Kao (1999). This was followed by Phillips and Ouliaris (1990) which prescribed the statistics and presented the following model: 


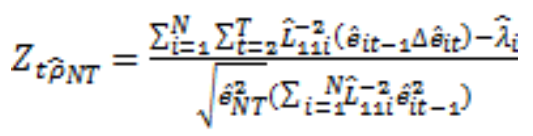

Where $\hat{\sigma}_{N T}=\frac{1}{N} \Sigma_{i=1}^{N} \frac{\hat{\sigma}_{i}^{2}}{\hat{\mathbb{L}}_{11 \mathrm{i}}^{2}}$.

Using Brownian motion, Pedroni found the following estimation:

$$
Z_{\text {top } \mathrm{NT}}+1.73 \sqrt{N} \Rightarrow(0,0.93)
$$

Whereby the similar hypotheses that (Ho: no cointegration; $H_{1}$ : cointegrated) were assumed.

The test also differentiated between the homogenous alternative (of within dimension that $\mathrm{y}=\mathrm{x} 1+\mathrm{x} 2+\mathrm{x} 3=\sum \mathrm{t}$ ) and the heterogeneous alternative (of between dimension that include the inverse function of $\mathrm{y}-\mathrm{x} 1-\mathrm{x} 2-\mathrm{x} 3=\sum_{\mathrm{t}}$ ). Pedroni (1999;2004) also had further tested the Kao (1999) technique which added the non-parametric (PhilipsPeron) and the parametric (ADF) tests with inclusion of HAC matrices for each cross-panel data. This showed a higher degree of power statistic needed in order to test the panel data for cointegration testing.

Finally, we used the simple panel static regression analysis without effects to determine the vertex model hypotheses. This is because the Generalization Moments Method (GMM) for a dynamic panel would be uncorrelated with time for this study. As a preliminary study, our sole intention was to estimate the first model without the influence of time and lags. Our earlier assumption was that the Error Component Regression would be uncorrelated in the hypothetical model because we did not account for the fixed effect (intercept) and the random effect (trend). It is because both the gradient and the constant need a more detailed analysis and this study can only focus on the stage of the pioneer vertex hypotheses. Both the fixed and the random effect models are presumed to not be influencing on the hypotheses' argument.

Therefore, we employed the following panel pool static model for the estimation:

$$
\dot{F}_{a b s}=\frac{\left.y\left[\Sigma^{-1}\left(z^{*}\left(z^{*} z^{-1} z^{*}\right)^{-1} z^{*}\right]-z\left(z \Sigma^{-1} z\right)^{-1} z^{*}\right) \Sigma^{-1}\right) y /(N-1) K^{*}}{\left(y^{*} \Sigma^{-1} y-y^{*} \Sigma^{-1} z^{*}\left(z^{*} \Sigma^{-1} z^{*}\right)^{-1} z^{*} \Sigma^{-1} y / N(T-K)\right.}
$$

Which consists of the F-panel distribution that each of $\left((\mathrm{N}-1) K^{a}, \mathrm{~N}\left(\mathrm{~T}-K^{a}\right)\right)$ was set for the degree of freedom, respectively. The above test was also the general test for a linear restriction as described in Roy (1957) and further used by Zellner (1962). As usual, we need to reject Ho, which is to conclude the significance of panel data.

\section{ANALYSIS}

We used numbering for cross sectional countries: Brunei - 1, Laos - 2, Myanmar - 3, Singapore - 4, Thailand 5, Vietnam - 6, Malaysia - 7, Cambodia - 8, Indonesia - 9, and Philippines - 10. We also applied the Levin, Lin and Chu (LLC) and Im, Pesaran and Shin (IPS) tests to determine the panel unit roots test. Table $1 \&$ Table 2 show the unit roots test results of both the LLC and IPS tests for all of the ASEAN countries.

The results indicated that all the variables contain the unit root and that the hypothesis of stationarity was to be rejected. The acceptance of these models at level $\mathrm{I}(\mathrm{O})$ would produce a spurious regression. However, at first differentiation, the I(1), t-statistic was greater than the t-probabilistic value, meaning that the null hypothesis was rejected (series did not contain unit root, hence they are stationary). From the LLC test, on the other hand, only one of the variables (fixed broadband) was not significantly stationary. This is because; the LLC test generally has less power of region in rejection. It was only after our experiment with the (IPS) test that we confirmed that all of the 
variables were significant and showed the strong stationarity values at I(1), for both the endogenous and exogenous variables This procedure is essential as it would be inaccurate if we proceeded to the ARDL approach without conducting the stationarity test in advance.

Table-1 Panel Unit Root Test Results

\begin{tabular}{|c|c|c|c|c|c|c|}
\hline \multicolumn{7}{|c|}{ PANEL UNIT ROOT TEST FOR VARIABLES - LEVIN, LIN \& CHU (LLC) } \\
\hline & \multicolumn{3}{|c|}{\begin{tabular}{|l|} 
Level \\
\end{tabular}} & \multicolumn{3}{|c|}{$\begin{array}{l}\text { First Difference } \\
\end{array}$} \\
\hline & None & Intercept & Trend and Intercept & None & Intercept & Trend and Intercept \\
\hline $\begin{array}{l}\text { AIR } \\
\text { PASSENGER }\end{array}$ & 6.53202 & 1.95101 & -2.44529 & $\begin{array}{l}-7.20077 \\
(* * *)(10)\end{array}$ & $\begin{array}{l}-8.37456 \\
(* * *)(10)\end{array}$ & $-7.41279\left({ }^{* * *}\right)(10)$ \\
\hline $\begin{array}{l}\text { FIXED } \\
\text { BROADBAND }\end{array}$ & 1.72745 & -15.0569 & -13.8166 & $\begin{array}{c}-9.08464 \\
(* * *)(8) \\
\end{array}$ & $\begin{array}{c}-5.02151 \\
(* * *)(8) \\
\end{array}$ & $-1.03131(8)$ \\
\hline MOBILE DATA & 3.09909 & -11.3641 & -2.60280 & $\begin{array}{c}-4.53169 \\
(* * *)(9)\end{array}$ & $\begin{array}{c}-1.49151 \\
(* *)(9)\end{array}$ & $-3.66679(* * *)(10)$ \\
\hline GNI & 10.2185 & -1.39501 & 1.84836 & $\begin{array}{l}-3.85939 \\
(* * *)(10)\end{array}$ & $\begin{array}{l}-14.1736 \\
(* * *)(10)\end{array}$ & $-12.6369\left(*^{* *}\right)(10)$ \\
\hline $\begin{array}{l}\text { TOURISM } \\
\text { EXPENDITURE }\end{array}$ & 7.91266 & -0.18428 & -2.84102 & $\begin{array}{c}-8.66119 \\
(* * *)(9) \\
\end{array}$ & $\begin{array}{c}-11.1213 \\
(* * *)(9) \\
\end{array}$ & $-8.69267(* * *)(9)$ \\
\hline TAX & 13.0679 & -0.49644 & -5.55878 & $\begin{array}{r}-5.27137 \\
(* * *)(8)\end{array}$ & $\begin{array}{c}-12.5796 \\
(* * *)(8)\end{array}$ & $-11.7225\left({ }^{*} * *\right)(8)$ \\
\hline
\end{tabular}

Note: For LLC test, the first result is t statistic value. All of the variables using SIC automatic chose lags from the e-view computer program. Optimal lags were chosen by Schwert (1989) Kernel: Bartlett and Bandwidth: Newey-West. For first differentiation value in parentheses $=$ significant level $*=10 \%$; $* *=5 \%$; $* * * 1 \%$. In second parentheses in first difference detail cross countries significant, Examples; $10=10$ countries significant)

Table-2. Panel Unit Root Test Results IPS

\begin{tabular}{|c|c|c|c|c|}
\hline \multicolumn{5}{|c|}{ IM, PESARAN AND SHIN (IPS) } \\
\hline & \multicolumn{2}{|c|}{ Level } & \multicolumn{2}{|c|}{ First Difference } \\
\hline & Intercept & Trend and Intercept & Intercept & Trend and Intercept \\
\hline AIR PASSANGER & 4.97371 & -1.01351 & $-11.2461(* * *)$ & $-8.85584(* * *)$ \\
\hline FIXED BROADBAND & 3.26994 & 4.07357 & $-2.95891(* * *)$ & $-5.82569(* * *)$ \\
\hline MOBILE DATA & -9.06237 & 2.95574 & -0.33464 & $-4.70979(* * *)$ \\
\hline GNI & 1.69348 & -0.05685 & $-12.1939(* * *)$ & $-8.24604(* * *)$ \\
\hline TOURISM EXPENDITURE & 2.10909 & -1.58823 & $-11.0738(* * *)$ & $-9.61553(* * *)$ \\
\hline TAX & 2.09661 & -5.66584 & $-10.8168(* * *)$ & $-8.92031(* * *)$ \\
\hline (All variables in pure logarithm function) & $\begin{array}{l}\text { Note: For IPS } \\
\text { computer proz } \\
\text { first difference } \\
\text { proxy of comn }\end{array}$ & $\begin{array}{l}\text { est first is W statistic value. All } \\
\text { am. Optimal lags choose by Schv } \\
\text { alue in parentheses = significa } \\
\text { n component no NONE will esti }\end{array}$ & $\begin{array}{l}\text { he variables using SIC } \\
\text { t (1989) Kernel: Bartle } \\
\text { level } *=10 \% ; * *=5 \\
\text { tes. }\end{array}$ & $\begin{array}{l}\text { omatic choosing lags from e-view } \\
\text { and Bandwidth: Newey-West. For } \\
* * *=1 \% \text {. Because of IPS using }\end{array}$ \\
\hline
\end{tabular}

We emphasized developing the basic vertex argument hypothesis. Table 3 shows the result of the panel long run cointegration test.

First, we used the Johansen-Fisher Panel Co integration test. The outputs showed a strong 1\% significant level for all of the countries, except Brunei and Myanmar at the three cointegrating factor. This is because it is hard to obtain balanced data from these two countries and derive the non-significant output of the Johansen-Fisher test. Nevertheless, eight countries out of ten in the sample indicated strong significance and evidence which support our hypotheses.

The major advantage of using the Johansen-Fisher test is that we can determine each component of cointegration, and this is vital in order to validate the hypotheses. Generally, the outcome indicated strong evidence of the impact of digital technology, macroeconomics and policy on air passenger volume in the ASEAN market.

Next, we applied the Kao (Engel-Granger based) Residual Cointegration Test. The test additionally supported the existence of strong cointegration among the variables at a minimum $1 \%$ level of significance with minimum of two lags. This implies that even after a two-year lag, the model stabilizes with strong significant level, denoted from the output of -2.433552 (t-statistic of $\mathrm{ADF}$ ) that was larger than the t-probabilistic value at a minimum $1 \%$ significance level.

We also used SIC with the intercept option, and the model has presented a more significant result by using the Static Panel data estimation rather than the dynamic and Error Component Regression Model. Nevertheless, the 
output from the Kao-Engel test suggests that the model can be verified using the dynamic model. We also tested and reconfirmed the analysis by using the Pedroni's Residual Cointegration Test (within-dimension as the homogenous alternative).

We applied the analysis within the dimension since the model was irreversible to validate the cointegration test, and the basic model was already sufficient. From the result, we identified that both of the PP and ADF statistic were significant at the $5 \%$ level which also stabilizes for two year lags. This was confirmed by the HAC lags that were significant and stable even when using the dynamic approach. The entire cointegration test applied was also indicating the significant existence of long-term relationships in the model, especially in the three robust types of relationship, at the $1 \%$ level of significance (Johansen-Fisher).

Table-3. Cointegration Test

\begin{tabular}{|c|c|c|c|c|c|c|}
\hline \multicolumn{3}{|c|}{ Johansen Fisher Panel Cointegration Test ${ }^{1}$} & \multicolumn{2}{|c|}{$\begin{array}{l}\text { Kao (Engel - Granger Based) } \\
\text { Residual Cointegration Test }{ }^{2}\end{array}$} & \multicolumn{2}{|c|}{$\begin{array}{l}\text { Pedroni Residual Co integration } \\
\text { Test } \\
\text { (homogenous alternative) }^{3}\end{array}$} \\
\hline Ho: $r \leq 3$ & $\begin{array}{ll}\text { Fis } & r \\
\text { Stat. } & \text { (trace } \\
\text { stat) } & \end{array}$ & $\begin{array}{l}\text { Fisher Stat. } \\
\text { (max-eigen test) }\end{array}$ & $\begin{array}{l}\text { t-statistic } \\
(\mathrm{ADF})\end{array}$ & $-2.4335 * * *$ & Panel v-statistic & -0.8084 \\
\hline 1 & Dropped & Dropped & $(\operatorname{RESID}(-1))$ & $-4.8643^{* * *}$ & Panel rho-statistic & 1.3456 \\
\hline 2 & $52.9815^{* * * *}$ & $28.7327^{*} * *$ & $\mathrm{D}(\operatorname{RESID}(-1))$ & $3.2292^{*} * *$ & Panel PP-statisti & $-1.8152^{* *}$ \\
\hline 3 & Dropped & Dropped & $\mathrm{D}(\operatorname{RESID}(-2))$ & -0.8214 & $\begin{array}{l}\text { Panel ADF- } \\
\text { statistic }\end{array}$ & $-2.3073^{* *}$ \\
\hline 4 & $52.732^{* * * *}$ & $25.437 \mathrm{O}^{* * *}$ & $\mathrm{D}(\operatorname{RESID}(-3))$ & $4.1258 * * *$ & & \\
\hline 5 & $59.8277^{*} * *$ & $39.0289^{* * *} *$ & \multirow{7}{*}{\multicolumn{4}{|c|}{ 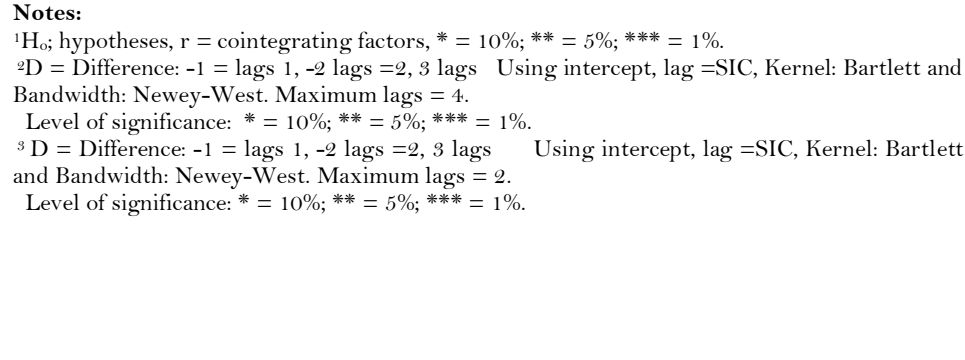 }} \\
\hline 6 & $37.8685^{* * * *}$ & $20.6896^{*}$ & & & & \\
\hline 7 & $45.0829^{* * * *}$ & $23.8126^{* * *}$ & & & & \\
\hline 8 & $46.5218^{* * * *}$ & $22.2895^{* * *}$ & & & & \\
\hline 9 & $50.1748^{* * * *}$ & $40.5023^{* * *} *$ & & & & \\
\hline 10 & $47.8655^{* * * *}$ & $27.3375^{* * *}$ & & & & \\
\hline \multicolumn{3}{|c|}{$\begin{array}{l}\text { Cross-sections: } \\
\text { 1: Brunei, 2: Laos, 3: Myanmar, } \\
\text { 3: Singapore, 5: Thailand, 6: Vietnam, } \\
\text { 7: Malaysia, 8: Cambodia, 9: Indonesia, and 10: Philippines }\end{array}$} & & & & \\
\hline
\end{tabular}

Table 4 shows the Panel Static Model which is relative to the earlier hypotheses. Following a lot of experiments using the static panel model, the output indicates that it was partially agreed on broadband's positive impact, despite the negative impact from mobile subscription on the air passenger's volume. Our findings were contradictory to the norms that in reality and based on experience, air passengers were more attracted to being able to use Wi-Fi rather than their mobile data.

The second hypothesis, which assumes digital globalization, states that a lot of people would be more likely to browse the internet using non-capped (or unlimited) internet quotas. ASEAN countries have also developed enough facilities and infrastructures which allows travelling over large distances while still accessing broadband (Wi-Fi). As proposed by the model, the ASEAN countries' governments should increase the Wi-Fi capacity and connectivity and that may increase the volume of the inbound and outbound passengers across the region.

Secondly as per our expectation, the GNI has a strong and solid significant correlation on the volume of air passengers. This suggests that the wealthier the country, the greater the inbound and outbound volumes of air passengers and tourists will be. Thirdly, tax policies and the volume of air passengers had a weak and negative relationship to each other. Even though the result showed a fair amount of significance at the $5 \%$ level, it implies that tax reform in the countries would only affect a small portion of the tourist and air passenger volume in the country.

Finally, an unexpected finding was revealed where tourism expenditure did not have any relationship to the volume of air passengers, because the variables did not show any significance signs, even at the $10 \%$ level. Even if the variable was significant, the output would imply that there is a negative relationship on the air passenger 
volume which raises controversy between these variables. Our hypotheses suggested that even if the data was stationary and cointegrated at least at the differentiation, the data itself might influence the estimation as some developing ASEAN countries provided an insufficient amount of data in order to execute the analysis between tourism expenditure and air passenger volume.

Table-4. Panel Static Model

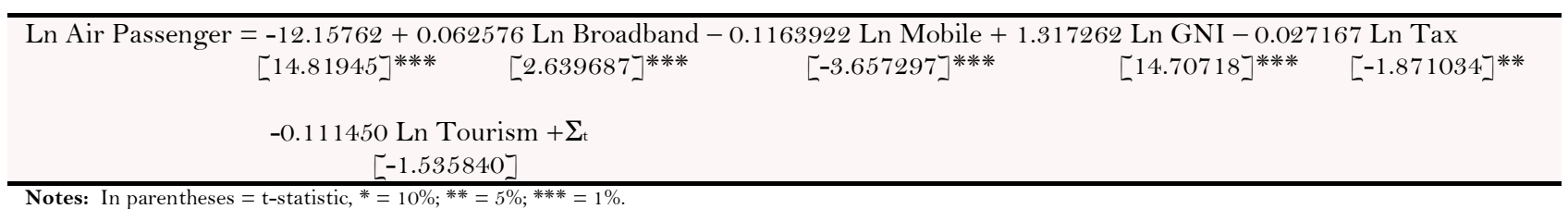

\section{VERTEX CURVE}

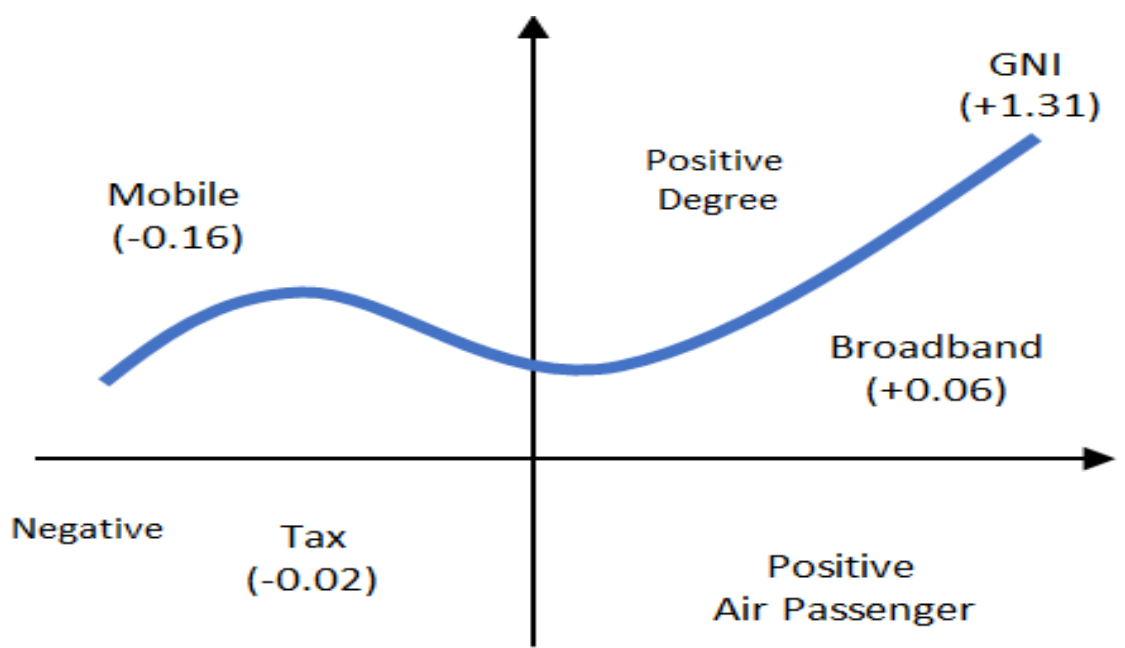

Diagram-1. Vertex Curve Hypotheses.

The above diagram shows the vertex curve hypotheses that were computed from the panel statistic output. The curve exhibited a cubic- like relationship. The $\mathrm{y}$-axis indicates the degree of power, while the $\mathrm{x}$-axis shows the relationship to the air passenger volume. Both axes depicted the positive (+ve) and negative (-ve) measurements. It is clearly indicated that the cubic relationship caused the vertex shape of the curve line.

Firstly, we found that tax has a weak -0.02 relationship with the air passenger volume. This means that, as expected by our earlier hypotheses that a tax regime will limit the inbound and outbound air passenger volumes. Therefore, if the policymakers in ASEAN countries are planning to cut the tax rate, tariffs or implement any other taxation tools, the air passenger volume would increase only as little as $2 \%$. Following this, we concluded that this tool is not the best option to increase air passenger volume.

Secondly, the mobile data plan seems to impact air passenger volume in a moderate negative manner (-0.16). This suggests that any increase in mobile data plans will decrease approximately $16 \%$ of the air passenger volume. This is a contradicting result as per our earlier estimation. A simple clarification for this argument is that due to more Wi-Fi user facilities, many ASEAN countries' have expensive internet charges and data-capping policy for mobile services which can impact the result and relationship negatively. This also indicates that there is a moderate positive relationship between broadband data (Wi-Fi) and the air passenger volume in the ASEAN market. The value of 0.06 means that improvements in broadband data would increase the volume of air passengers in the ASEAN market by $6 \%$. This argument is supported by the underlying theory but is not exactly as per our expectations. This is because we assumed that the variable was the major cause of air traveling, but in contrary, our estimates of the impact were mediocre. Therefore, as the digital world develops towards the capacity of $5 \mathrm{G}$ band 
and li-fi (light-fidelity) types, the impact would still be important enough to push up the air passenger volume in the ASEAN region.

Finally, the impact of the GNI (Gross National Income) on air passenger volume was around +1.31 . This is a strong indication that national income has a high impact on air passenger volume and can increase it by $131 \%$. Thus, industry and government should work on their internal economy to increase the GNI and the air passenger volume.

For example, Singapore has had tremendous economic growth and is categorized as a developed state and this may have led to more tourists, air passengers, or transit passengers. As the country is controlling a substantial amount of air traffic, it is indicates that the mobility of labour and product induces economic growth. Another variable of concern, the tourism, unfortunately was not determined as having enough influence on air passenger volume and therefore not valid enough to be included in our model.

To conclude, we summarized that the vertex of policy-impact hypotheses (tax-air passenger) has a light impact, digital-impact hypotheses (broadband \& mobile - air passenger) has a mediocre and substitution impact, while the macroeconomics-impact hypotheses (GNI - air passenger) has a strong but partial (that only GNI was valid) impact. This further show that the national income was the major key to increasing the air passenger volume and is the peak of the vertex.

Through policymakers and industrialists, the fundamentals of internal economic growth must be improved to increase the air passenger volume, as it would further impact the internal economic capacity through GNI. The air passenger volume may rise more than twice from this strategy and could bring the cycle back towards the income growth of the nation. Since this article was just a pilot study, we would propose that more tests be conducted in the future by using the dynamic and non-linear approach with the error component regression. In conjunction to this, the in-depth enveloped theorem analyses of the vertex curve should also be promoted.

Funding: The authors are grateful for the financial support provided by the Institute of Quality and Knowledge Advancement (INQKA), at the Universiti Teknologi Mara (UiTM), Malaysia that enabled the successful completion of this research paper.

Competing Interests: The authors declare that they have no competing interests.

Contributors/Acknowledgement: All authors contributed equally to the conception and design of the study.

\section{REFERENCES}

Engle, R.F. and C. Granger, 1987. Co-integration and error correction: Representation, estimation, and testing. Econometrica, 55(2): 251-276.Available at: https://doi.org/10.2307/1913236.

Fisher, F.M., 1970. Tests of equality between sets of coefficients in two linear regressions: An expository note. Econometrica, 38(2): 361-366.Available at: https://doi.org/10.2307/1913018.

Hanaoka, S., M. Takebayashi, T. Ishikura and B. Saraswati, 2014. Low-cost carriers versus full service carriers in ASEAN: The impact of liberalization policy on competition. Journal of Air Transport Management, 40(C): 96-105.Available at: https://doi.org/10.1016/j.jairtraman.2014.06.008.

Hensher, D.A. and C. Duangphastra, 2000. Interorganizational support and strategies for the ASEAN aviation sector: An application of canonical correlation analysis. Journal of Air Transport Management, 6(3): 119-132.Available at: https://doi.org/10.1016/s0969-6997(00)00002-8.

Im, K.S., M.H. Pesaran and Y. Shin, 2003. Testing for unit roots in heterogeneous panels. Journal of Econometrics, 115(1): 5374.Available at: https://doi.org/10.1016/s0304-4076(03)00092-7.

Kao, C., 1999. Spurious regression and residual-based tests for cointegration in panel data. Journal of Econometrics, 90(1): 144.Available at: https://doi.org/10.1016/s0304-4076(98)00023-2.

Lee, C. and Y. Fukunaga, 2014. ASEAN regional cooperation on competition policy. Journal of Asian Economics, 35(C): $77-$ 91.Available at: https://doi.org/10.1016/j.asieco.2014.09.005. 
Levin, A., C.-F. Lin and C.-S.J. Chu, 2002. Unit root tests in panel data: Asymptotic and finite-sample properties. Journal of Econometrics, 108(1): 1-24.Available at: https://doi.org/10.1016/s0304-4076(01)00098-7.

Lin, J.-J. and C.-Y. Fu, 2014. The opening of direct flights across the Taiwan Strait: the impact on the global role of Taiwan's international airport. Journal of Transport Geography, 39: 179-186.Available at: https://doi.org/10.1016/j.jtrangeo.2014.07.008.

Maddala, G.S. and S. Wu, 1999. A comparative study of unit root tests with panel data and a new simple test. Oxford Bulletin of Economics and Statistics, 61(S1): 631-652.Available at: https://doi.org/10.1111/1468-0084.61.s1.13.

Pedroni, P., 1999. Critical values for cointegration tests in heterogeneous panels with multiple regressors. Oxford Bulletin of Economics and Statistics, 61(S1): 653-670.Available at: https://doi.org/10.1111/1468-0084.0610s1653.

Pedroni, P., 2004. Panel cointegration: Asymptotic and finite sample properties of pooled time series tests with an application to the PPP hypothesis. Econometric Theory, 20(3): 597-625. DOI https://doi.org/10.1017/s0266466604203073.

Pesaran, M.H., 2007. A simple panel unit root test in the presence of cross-section dependence. Journal of Applied Econometrics, 22(2): 265-312.Available at: https://doi.org/10.1002/jae.951.

Phillips, P.C.B. and S. Ouliaris, 1990. Asymptotic properties of residual based tests for cointegration. Econometrica, 58(1): 165193.Available at: https://doi.org/10.2307/2938339.

Roy, S.N., 1957. Some aspect of multivariate analysis. New York: John Wiley.

Schwert, G.W., 1989. Why does stock market volatility change over time? The Journal of Finance, 44(5): 1115-1153.Available at: https://doi.org/10.1111/j.1540-6261.1989.tbo2647.x.

Tan, A.K.-J., 2015. The proposed EU-ASEAN comprehensive air transport agreement: What might it contain and can it work? Transport Policy, 43(C): 76-84.Available at: https://doi.org/10.1016/j.tranpol.2015.05.009.

Wu, C., Q. Jiang and H. Yang, 2018. Changes in cross-strait aviation policies and their impact on tourism flows since 2009. Transport Policy, 63(C): 61-72.Available at: https://doi.org/10.1016/j.tranpol.2017.11.008.

Zellner, A., 1962. An efficient method of estimating seemingly unrelated regressions and tests for aggregation bias. Journal of the American Statistical Association, 57(298): 348-368.Available at: https://doi.org/10.1080/0162 1459.1962.10480664.

Views and opinions expressed in this article are the views and opinions of the author(s), Asian Economic and Financial Review shall not be responsible or answerable for any loss, damage or liability etc. caused in relation to/arising out of the use of the content. 